\title{
Analyzing Trend and Pattern of Agricultural Drought: A Case Study of Karnali And Sudurpashchim Provinces
}

\author{
Naresh Bista, Dikpal Mahat, Sachin Manandhar, Binayak Regmi, Uma Shankar Panday, Shashank Karki \\ nareshbista9@gmail.com, abinashmahat234@gmail.com, regmibinay56@gmail.com, sacheenmdr9@gmail.com, \\ uspanday@ku.edu.np, Shashank.karki480@gmail.com
}

\section{KEYWORDS}

Agricultural Drought, Drought Severity Index, DSI Map, Monitoring, Climate Change

\begin{abstract}
A drought is a period of time when an area or region experiences below-normal precipitation, with characteristics and impacts that can vary from region to region. Agricultural Drought analyzes and reflects the extent of the soil moisture and morphology of crop. Deficient rainfall in the winter of 2008 resulted in a severe drop in crop production right across the country. So, there is a necessity of assessment of drought events to make informed and timely decisions. The main focus of our study is to monitor the agricultural drought in Karnali and Sudurpashchim provinces of Nepal. The condition of drought in Karnali and Sudurpashchim provinces from 20012020 wereanalysed with the help of Drought Severity Index. MODIS NDVI (MOD13) and MODIS ET-PET (MOD16) datasets were used to monitor and analyze the trend and pattern of agricultural drought scenario. Both datasets were then normalized for DSI calculation and the DSI result was used to monitor and to analyze the trend and pattern in the agricultural drought scenario. Further, trend and pattern analyses were performed in terms of landcover, ecological zones, and the variation of DSI. After completion of this project, we can conclude that the Maximum dryness was found in March, it might be due to less NDVI and increase in evapotranspiration rate and maximum wetness in November. Agricultural area experienced more drought variation than other landcover zones
\end{abstract}

\section{INTRODUCTION}

A drought is a period of time when an area or region experiences below-normal precipitation, with characteristics and impacts that can vary from region to region (Cousteau, 2020).Drought is as low-onset natural hazard with effects that accumulate over a considerable period of time (weeks to months). The frequency and intensity of extreme climate events like drought have increased significantly(WMO, 2016).Since extreme climate events tend to be more abnormal, unexpected, unpredictable, and sensitive to climate change, they are considered the main source of terrestrial ecosystem instability and have a substantial impact on sustainable development of both ecosystems and human economy (LIU, 2016).

The absence of exact and widespread definition for dry drought prompts disarray about when a dry season starts and when it ends and the exact chance to execute crisis reaction activities or relief measures(WMO, 2016).Agricultural drought is mainly concerned with water deficit in crops because of a reduction in water supply in the soil, loss of soil moisture caused by decreases in precipitation (Wilhite \& Glantz, 1985).It is associated with various subjects like agriculture, meteorology, hydrology, and 
plant physiology and consists of both natural and artificial systems (LIU, 2016).

Although, Agricultural drought is important for reducing disaster loss and impact, it is still poorly understood. Drought is recognized as a natural hazard which occurs with varying frequency in all climatic regimes due to climatic variability (NOAA, 2019). Concerns about drought, in terms of its frequency, intensity and duration, has grown world-wide, mainly in the countries like Nepal which are vulnerable to natural and human caused disasters. The country is highly reliant upon the regular availability of water for agricultural use. Drought is most significant in western part of Nepal, where the availability of water is limited and agriculture production is reliant on rainfall. Due to which, there is a drop in production of crops and might lead to risk of food insecurity.

\subsection{Problem Statement}

Nepal is one among the foremost the vulnerable countries with respect to climate change, due to greater warming in recent years than that of the global average (MoHA, 2009). These conditions have created a drought condition especially for the rain-fed hill farming system, where people depend on summer and winter rainfall for their major agricultural activities (Adhikari, 2018). Due to different causes like the lack of research on suitable index, inconsistency in precipitation and the rainfall pattern, lack of real time monitoring system etc. had caused the situation worst. So, there's a necessity of timely assessment of drought events for decision making.

\section{STUDY AREA}

Karnali Province is one of the seven federal Provinces of Nepal with the total area of 27,984 square kilometers (WIkipedia, 2020). It has some of the most remote and economically depressed areas of the country which are vulnerable to number of disasters including drought. Some regions (Mugu, Dolpa, Humla, Kalokot, Jajarkot) are permanently food deficit and despite food supply to these regions, it differs annual food deficit at least one-fourth requirement almost every year where crop yields are very poor.

Sudurpashchim Province is also one of the seven provinces of Nepal with the total area of 19,539 square kilometers lying within the region of latitude $28^{\circ} 12^{\prime}$ to $30^{\circ} 28^{\prime}$ 'and longitude $80^{\circ} 03^{\prime}$ to $81^{\circ} 50^{\prime}$.Most villages are very remote and inaccessible. Agriculture is the main source of livelihood where major crops are wheat, paddy, maize, garlic, mustard etc.

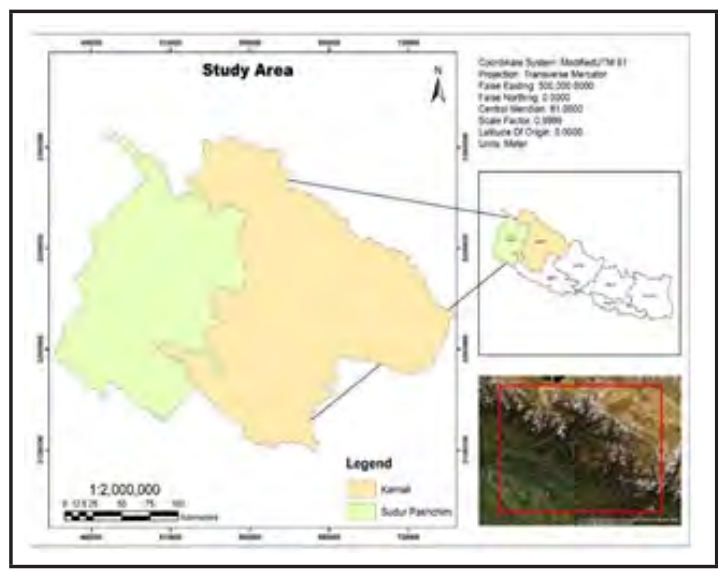

Figure 1: Study Area of Karnali and Sudurpashchim Province

\section{METHODOLOGY}

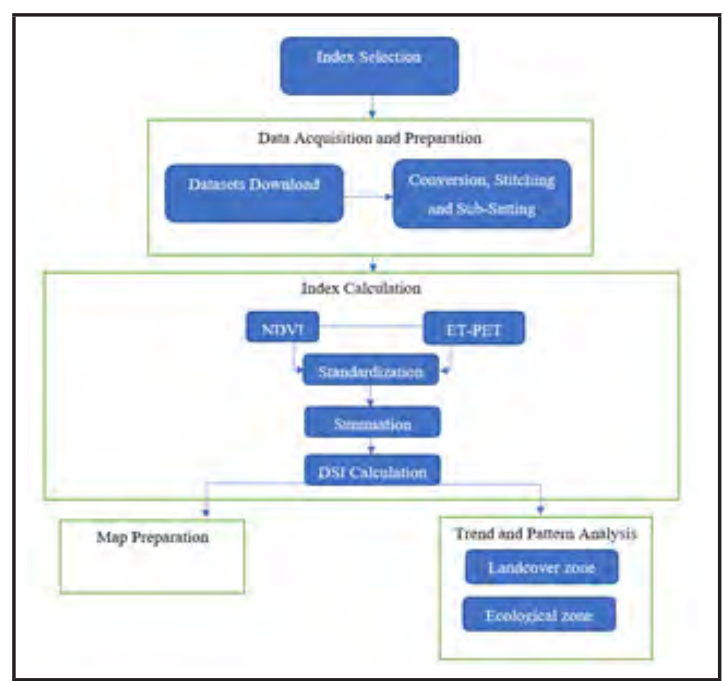

Figure 2: Workflow Diagram of Drought Monitoring 


\subsection{Index Selection}

Drought index value is a number which is more useful than the raw information (Hayes, 2002).Drought Severity Index (DSI), which is the integration of NDVI and ETPET was selected for the project because Drought Severity Index (DSI) can be produced at a $500 \mathrm{~m}$ spatial resolution and can be used for a wide range of water-resource and ecological applications. DSI from NDVI and ET-PET is generally effective for characterizing moisture conditions at the province level, with better performance in rainfed-dominated than irrigation-dominated regions and it can be used for near-real-time drought monitoring with fine resolution across subtropical or other similar regions.

\subsection{Data acquisition and Preparation}

\subsection{Datasets Download}

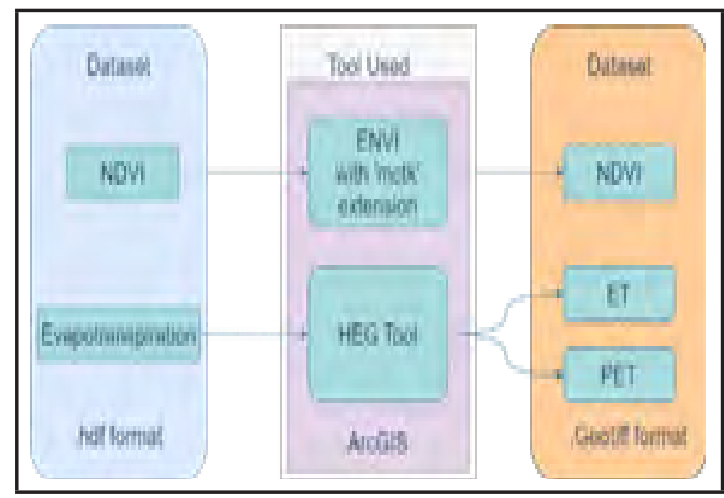

Figure 3: Data Preparation Chart

Two different datasets, MOD13 for NDVI and MOD16 for ET-PET were accessed from MODIS archives. MODIS NDVI is a global vegetation dataset for drought monitoring and trend analysis. Global monthly NDVI data was downloaded for five months (Nov- Mar) from 2000 for 20 years with Spatial and Temporal resolution of $500 \mathrm{~m}$ and 30 days respectively.

Similarly, MODIS ET-PET, a vegetation index, ratio of actual to potential evapotranspiration and useful for monitoring crop performance during the growing season and based upon availability of water for the crop. For MOD16, images were downloaded also with $500 \mathrm{~m}$ and 30 days spatial and temporal resolution.

\subsubsection{Data Conversion, Stitching and Sub- setting}

The downloaded datasets from MODIS archives were in HDF file formats. ENVI software with MCTK extension tool was used for conversion of NDVI HDF file to Geotiff file format. Similarly, HEG tool was used to for conversion of ET-PET HDF file format to Geotiff file format. Similarly, ENVI was used for data stitching and ArcGIS was used for data sub-setting.

\subsection{Index Calculation}

Collected ET-PET and NDVI datasets were used to calculate a new DSI value as an index as given in chart below:

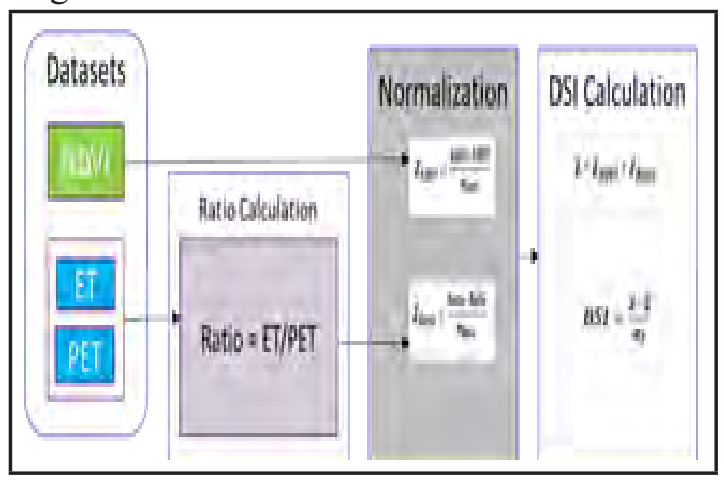

Figure 4: DSI Calculation Method

\section{Trend and Pattern Analysis}

Zonal statistics of DSI was calculated to get the trend and pattern with respect to landcover and ecological zones.

\subsection{Landcover Zone}

The obtained DSI value results were analyzed in terms of landcover change for 9-year time interval. Average DSI value were obtained for different landcover such as forest, grassland, wetland, agriculture, urban and barren land. The trend and pattern were analyzed with the help of bar plot. 


\subsection{Ecological zone}

The obtained DSI value results were analyzed in terms of ecological study for 5-year time interval. Average DSI value were obtained for ecological zones as Mountain, Hilly and Terai. The trend and pattern were analyzed with the help of bar plot.

\section{MAP PREPARATION}

The output DSI was reclassified according to DSI classification referred by NASA as in table below and DSI maps of five months for 20 years were prepared.

\section{Table 1: DSI Categorization}

\begin{tabular}{|c|c|c|c|}
\hline DSI range & Description & DSI range & Description \\
\hline-1.5 or less & Extreme drought & 0.3 to 0.6 & Incipient Wet \\
\hline-1.5 to -1.2 & Severe Drought & 0.6 to 0.9 & Slightly Wet \\
\hline-1.2 to -0.9 & Moderate Drought & 0.9 to 1.2 & Moderately Wet \\
\hline-0.9 to -0.6 & Mild Drought & 1.2 to 1.5 & Very Wet \\
\hline-0.6 to -0.3 & Incipient Drought & 1.5 or more & Extreme Wet \\
\hline-0.3 to 0.3 & Near-Normal & & \\
\hline
\end{tabular}

Source:(US Department of Energy, 2013)

\section{RESULT}

\subsection{DSI Map Preparation}

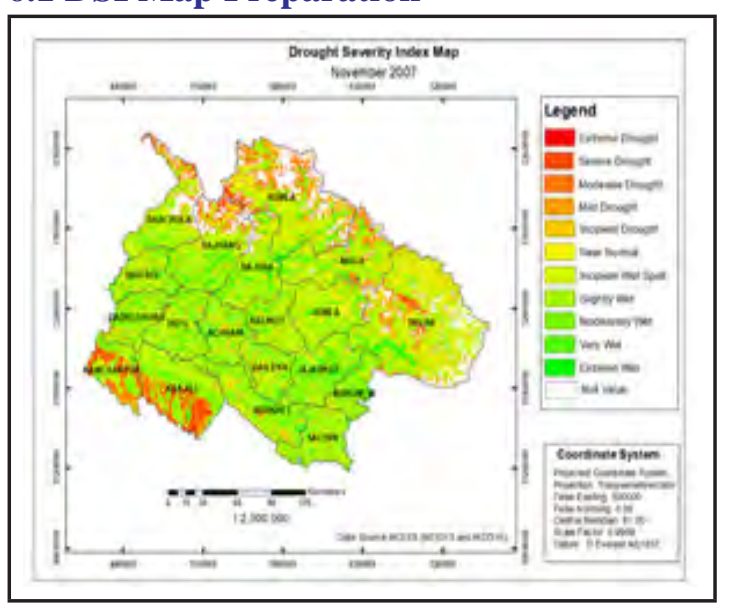

Figure 5: DSI Map of November 2007

Result shows, there is Moderate drought at some portions of Kanchanpur and Kailali. There is slightly wet condition in almost all hilly districts. Map shows some portions of
Humla, Mugu and Dolpa had experienced Mild drought condition at the beginning of season. Also, the white portion on the map denotes no Value which represents snowy area.

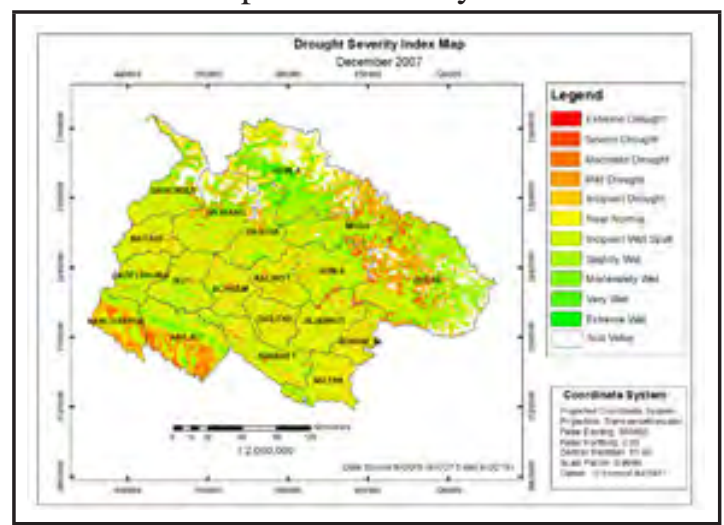

Figure 6: DSI Map of December 2007

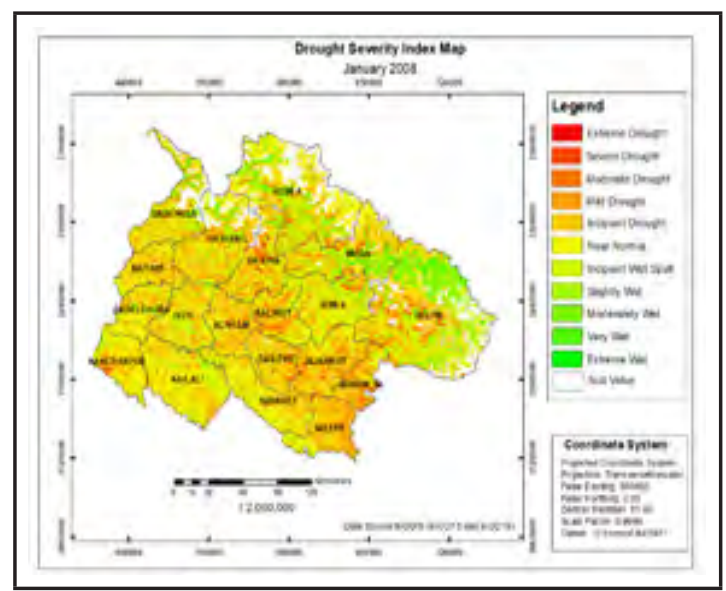

Figure 7: DSI Map of January 2008

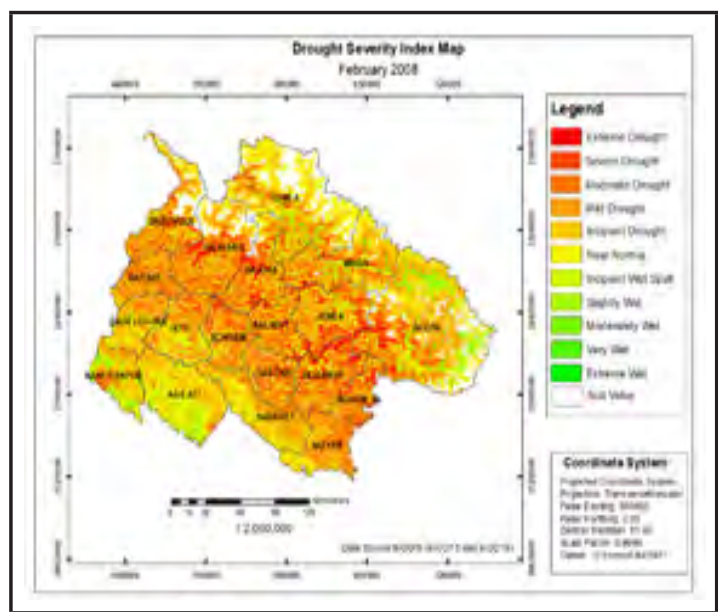

Figure 8: DSI Map of February 2008 


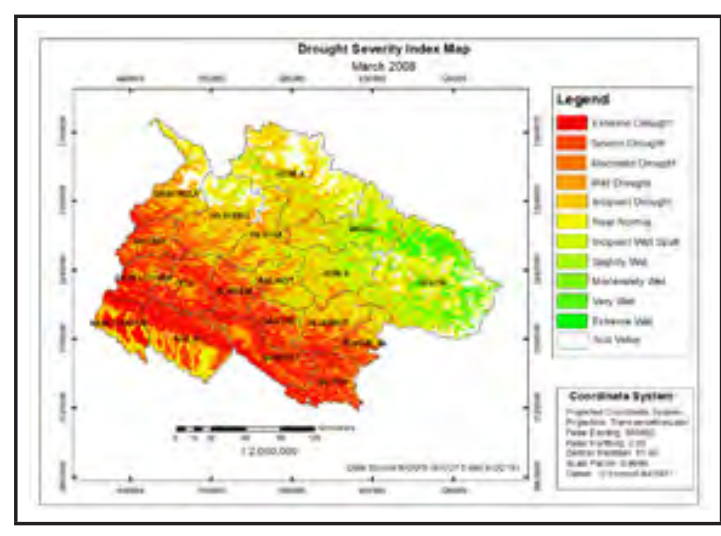

Figure 9:DSI Map of March 2008

Result shows, there was near-normal drought in almost all area in December and January. In February, there was moderate drought in hilly region and near-normal in some terai and mountain region. At the end of season, there was Extreme drought in terai area, NearNormal in hilly region and slightly wet in Mugu and Dolpa District.

The trend of drought from November to March is decreasing from wet to extreme dry but the opposite trend in some portions of Kailali and Kanchanpur is due to wetlands where the availability of water is unpredictable.

\subsection{Yearly Drought Variation}

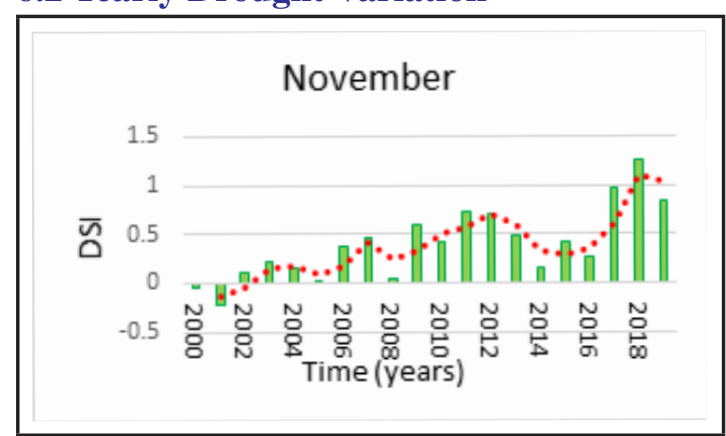

Figure 10: Bar plot of yearly variation of DSI in November

Result shows negative values in November of 2000-2001 which means there was dry condition then positive values from 2002, increasing DSI values and suddenly decreased at 2005 and 2008. From 2009, the drought condition in November at the beginning of season is wet till 2019.

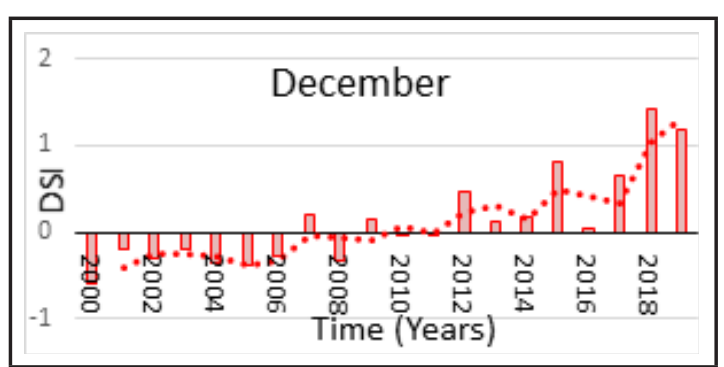

Figure 11: Bar plot of yearly variation of DSI in December

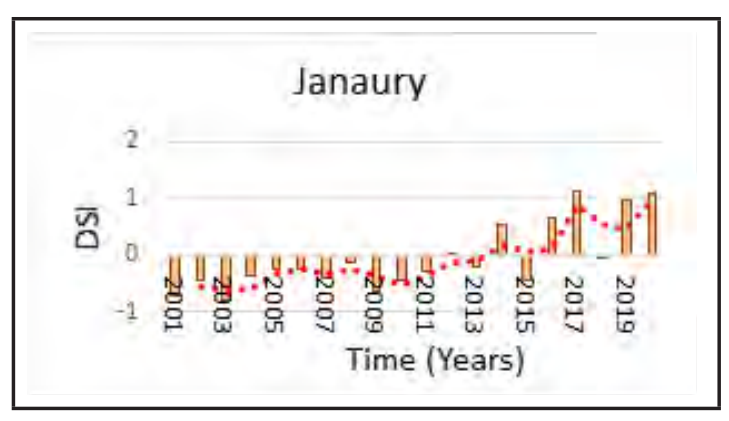

Figure 12: Bar plot of yearly variation of DSI in January

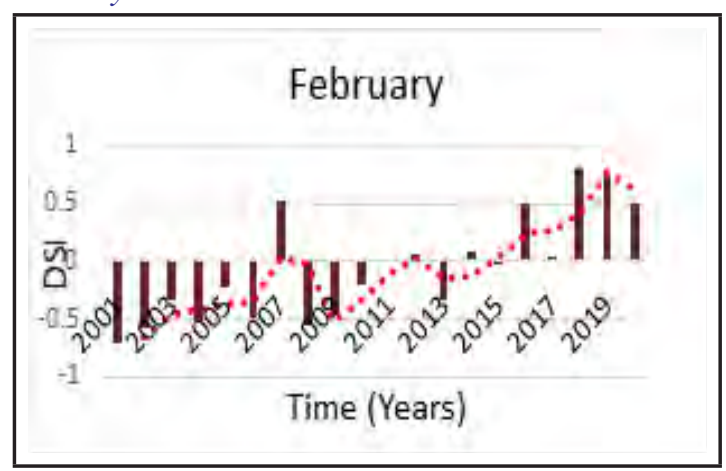

Figure 13: Bar plot of yearly variation of DSI in February

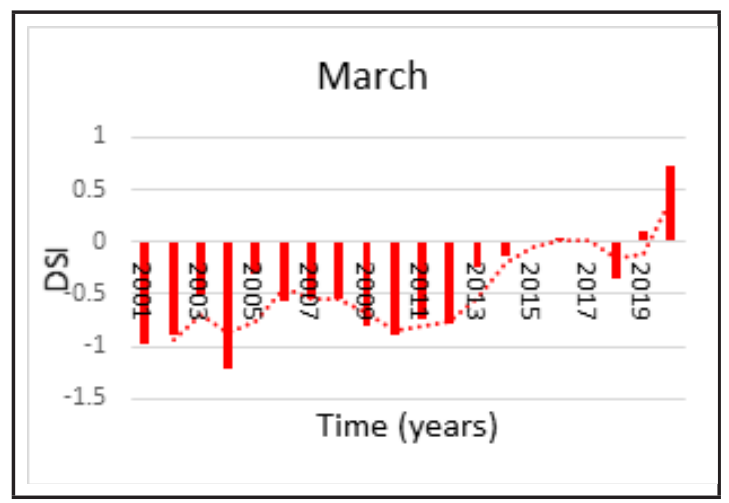

Figure 14: Bar plot of yearly variation of DSI in March 
In December, there was dry condition from 2001 to 2008 and wet condition from 2009 to 2020 and the highest value was in 2018. Results show negative values from 2001 to 2010 and positive values from 2011 to 2020 in January and in February, there are negative values from 2001 to 2011 and positive values from 2012 to 2020. In March, all year except 2015, 2016, 2017, 2019 and 2020 have negative values and there is highest value in 2020 .

Results show Minimum DSI value in March 2004 (Severe Drought), Maximum DSI value in December 2018 (Very Wet) and November experiences wetness in average and March experiences dryness in average.

There are great deviations in the drought in the season of the year 2004, 2006, 2008, and 2009 from 2000-2020 in which the drought condition was worse than in other year. The result coincides with the fact that the season of year 2006, 2008 and 2009 was the worst of all seasons.

\subsection{Trend and Pattern Analysis \\ 6.3.1 Landcover Study}

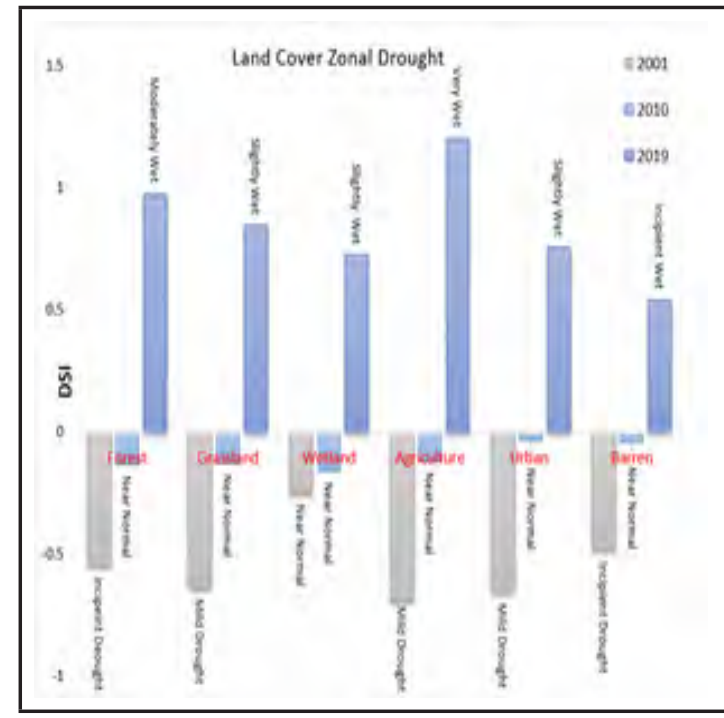

Figure 15: Bar plot of DSI with Landcover zones
The map results show that in year 2001, the lowest drought index value is in agricultural lands that is agricultural lands had experienced high drought conditions than other lands. Comparatively, forest and Barren lands had experienced low drought than urban and grasslands. The result show there is low drought in wetlands than other lands.

The result shows the lowest DSI value in wetlands which means wetlands had experienced extreme drought. After wetlands, the high drought condition is in forest, grasslands and agricultural lands respectively. In the season of 2019, DSI value is in agricultural lands which means agricultural lands had experienced severe wet condition in 2019 due to decrease in mean surface temperature causing wetness after 2010.

In year 2001 and 2010, average DSI value is negative but in the season of 2019 average DSI value is positive which is due to the availability of water resources, lower temperature. The maximum change in DSI value is in Agricultural area (From -0.6926 in 2001 to 1.2065 in 2020).

\subsubsection{Ecological study}

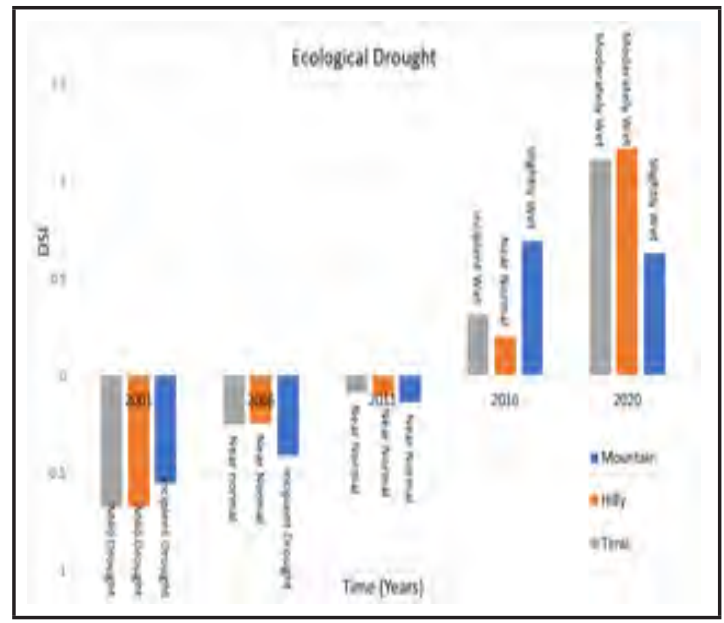

Figure 16: Bar plot of DSI with Ecological zones 
As result shows, in 2001 lowest mean DSI value is in hilly region and Mountain region has the highest mean DSI value which means comparatively better condition in mountain region than others. As shown, in 2006 mountain region has the lowest negative and hilly region has the highest negative DSI value than other regions.

Result shows in the season of 2011 lowest negative DSI value is in mountain region and highest in terai region that means terai region experienced better drought condition than other regions. Also, in the season of 2016, highest positive DSI value in mountain region and lowest positive in hilly region which means hilly region had experienced worst drought condition than other regions. Similarly, in the year of 2019, lowest DSI value is in mountain region and highest in hilly region which means mountain region had experienced worst drought condition.

\section{CONCLUSION}

This study discussed the condition of drought in of Karnali province and Sudurpashchim province from 2001- 2020 with the help of Drought Severity Index.

Result shows the maximum change in DSI value from Land Cover study in Agricultural area (-0.692632 (2001) to 1.206597 (2020)). Since land use in Agricultural area changes in different time of year according to the stage of the plant from vegetation to cutting stage which changes the NDVI value of the given region. From ecological study, results showed the highest positive DSI value in mountain region and lowest positive in hilly region which means hilly region had experienced worst drought condition than other regions. Furthermore, result showed that year 2008 had faced the worst drought in given 20 years.

\section{REFERENCES}

Adhikari, S. (2018). Drought Impact and Adaptation strategies in the Mid-Hill Farming system of Western Nepal.

Cousteau, A. (2020). Education. Retrieved from National Geographic: https://www. nationalgeographic.org/encyclopedia/ drought/

Hayes, M. (2002). Drought Indices. International Journal of Climatology, p. 18.

LIU, X. (2016). Agricultural drought monitoring: Progress, challenges, and. Journal of Geographical Sciences .

MoHA, M. o. (2009). Nepal Disaster Report.

NOAA. (2019). Climate Monitoring. Retrieved from National Centres For Environmental Information : https:// www.ncdc.noaa.gov/monitoringreferences/dyk/drought-definition

US Department of Energy. (2013). A Remotely Sensed Global Drought Severity Index. 361. Retrieved from http:// digitalcommons.unl.edu/usdoepub/361

WIkipedia. (2020). Economy of Nepal. Retrieved from Wikipedia, the free encyclopedia: https:// en.wikipedia.org/wiki/Economy_ of_Nepal\#: :text=Agriculture $\% 20$ remains $\% 20 \mathrm{Nepal}$ s $\% 20$ principal $\% 20$ economic, and $\% 20$ providing $\% 20$ $31.7 \% 25 \% 20$ of $\% 20$ GDP.

Wilhite,D., \&Glantz,M.(1985).Understanding the Drought Phenomenon: The Role of Definitions. Water International, 111120. Retrieved from National Drougght Mitigation Center.

WMO, W. M. (2016). National Drought Policies. 


\section{ACKNOWLEDGEMENT}

We, Sachin Manandhar, Naresh Bista, Binayak Regmi, Abinash Mahat would like to express our great gratitude towards the Survey Department of Nepal for considering our paper to publish in the Journal of Survey Department. Furthermore we are grateful towards our supervisor Asst.Prof. Uma Shankar Panday and Er. Shashank Karki, Department of Geomatics Engineering, Kathmandu University for their constant guidance, advice and every possible help. Without them this project had not been possible to be completed. Furthermore we are also grateful towards our Mr. Shangharsha Thapa for suggesting and providing insights during our project.

Nevertheless, we would like to thank our colleagues, family and everyone who helped us to their maximum extent for making this project a success. Their support and guidance played a vital role. We convey our finals thanks to all our friends with whom, we had privilege of interacting and working for the completion of the project.

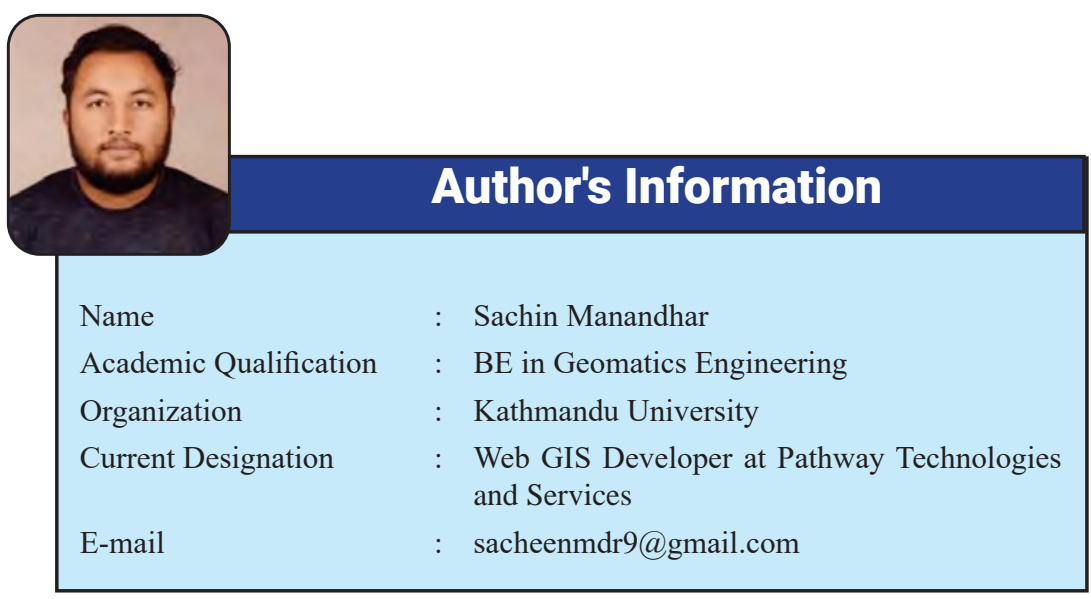

